\title{
Utilization of Archived Plasma to Detect Epidermal Growth Factor Receptor Mutation in Non-Small Cell Lung Cancer Patients
}

\author{
Ae-Chin Oh, Jin Kyung Lee,, Ji-Young Kim, ${ }^{1,2}$ Heon-Ok Jin, ${ }^{2}$ Jae Won Jung, \\ Yoon Hwan Chang, and Young Jun Hong ${ }^{1}$
}

Precision medicine has received increased attention as an effective approach for the treatment of cancer patients. Because of challenges associated with the availability of archived tissue, liquid biopsies are often performed to detect cancer-specific mutations. One of the major advantages of the liquid biopsy is that the treatment can be monitored longitudinally, even after the tumor tissue is no longer available. In a clinical setting, one component of precision medicine is the detection of cancer-specific mutations using archived samples. In this study, we evaluated the epidermal growth factor receptor (EGFR) mutation status of samples of lung cancer patients stored before introduction of the plasma EGFR test at our institution. The aim of this study was to validate the utility of archived plasma samples for detection of the EGFR mutation in nonsmall cell lung cancer (NSCLC) patients. The Cobas ${ }^{\circledR}$ EGFR Mutation Test v2 was the first liquid biopsy test approved as a companion diagnostic test for patients with NSCLC treated with tyrosine kinase inhibitors. We tested for the EGFR mutation in 116 plasma samples archived in the biobank, and the results were compared with those obtained in the tissue or cytology EGFR mutation test. The EGFR mutation-positive rate from archived plasma was lower than that determined from tissue or cytology at $19.0 \%$ and $53.4 \%$, respectively, and the concordance rate between the two tests was $58.6 \%$. Of interest, five (4.3\%) samples showed the T790M mutation in the plasma test, whereas this mutation was only detected in two (1.7\%) tissue/ cytology samples. Five (4.3\%) samples were additionally positive in the plasma test. Overall, these results indicate that archived plasma samples can serve as an alternative source for the plasma EGFR mutation test when tissue samples are not available, and can improve precision medicine and long-term follow-up in a noninvasive manner.

Keywords: precision medicine, liquid biopsy, nonsmall cell lung cancer, plasma EGFR, archived plasma, biobank

\section{Introduction}

$\mathrm{P}$ RECISION MEDICINE IS an emerging strategy for treating a disease according to specific genetic abnormalities of individual patients ${ }^{1,2}$ and has received increasing attention as an effective approach for the treatment of cancer patients. ${ }^{1-5}$ One example of a precision medicine approach involves use of a companion test-treatment paradigm to classify patients into groups according to the likelihood of their response to a given treatment based on the presence of certain genetic markers. ${ }^{1,2}$ Gradual adoption of a precision medicine approach requires detecting cancer-specific mutations retrospectively in certain cases for patients who have already been diagnosed and treated without having under- gone a molecular test. Thus, the previous mutation status needs to be tested using archived samples. Maintaining archived specimens in a biobank is valuable to allow for such retrospective testing. ${ }^{6}$ Biobanking involves the collection, processing, transport, storage, and retrieval of biospecimens for future purposes. .,8 $^{\text {to }}$

Liquid biopsy, consisting of biomarker testing, for example, mutations in cell free DNA (cfDNA), has emerged as an important approach to guide therapeutic decisions. ${ }^{9-13} \mathrm{~A}$ liquid biopsy is generally accompanied by simple blood collection and can enable real-time follow-up. Because of challenges associated with the availability of archived tissue, liquid biopsies are often performed to detect cancerspecific mutations. One of the major advantages of liquid

\footnotetext{
${ }^{1}$ Department of Laboratory Medicine, Korea Cancer Center Hospital, Seoul, Republic of Korea.

${ }^{2}$ KIRAMS Radiation Biobank, Korea Institute of Radiological and Medical Sciences, Seoul, Republic of Korea.
}

(C) Ae-Chin Oh et al., 2019; Published by Mary Ann Liebert, Inc. This Open Access article is distributed under the terms of the Creative Commons Attribution Noncommercial License (http://creativecommons.org/licenses/by-nc/4.0/) which permits any noncommercial use, distribution, and reproduction in any medium, provided the original author(s) and the source are cited. 
biopsy is the ability to monitor a treatment response longitudinally, even after the tumor tissue is no longer available. Moreover, collection is minimally invasive for the patient and can easily be repeated over time, allowing for more comprehensive analysis of tumor heterogeneity. ${ }^{11}$

Non-small cell lung cancer (NSCLC) accounts for $\sim 80 \%$ of all lung cancer cases, and remains one of the leading causes of cancer-related mortality worldwide. ${ }^{14-18}$ Approximately $10 \%, 13 \%$, and $35 \%$ of NSCLC patients in the United States, Europe, and East Asia, respectively, harbor epidermal growth factor receptor (EGFR) mutations ${ }^{19,20}$ with the most common mutations reported as being an exon 19 deletion and exon 21 L858R mutation. ${ }^{15-18}$ NSCLC patients with EGFR mutations benefit from treatment with EGFR-tyrosine kinase inhibitors (TKIs) such as afatinib, erlotinib, or gefitinib. ${ }^{14,15,19}$ Despite the generally high response rate, most patients develop resistance to TKIs after a median period of 12 months, which is more common in patients with the EGFR exon 20 T790M mutation, accounting for approximately half of all instances of acquired resistance to first-line EGFR TKI therapy. ${ }^{17,19,20}$

A tissue-based EGFR mutation test has been considered the gold-standard test for detection of EGFR mutation to date. ${ }^{10,20}$ However, this test is not possible for a considerable number of patients, especially after chemotherapy, for various reasons, including an insufficient amount of tumor tissue, unapproachable location for biopsy, poor patient conditions, and tumor heterogeneity. ${ }^{20-22}$

The Cobas ${ }^{\circledR}$ EGFR Mutation Test v2 (Roche Molecular System, Inc., NJ) was developed as a real-time PCR-based assay for qualitative detection of mutations of the $E G F R$ gene in NSCLC patients. In 2016, the Cobas EGFR Mutation Test v2 became the first liquid biopsy test that received approval from the US Food and Drug Administration (FDA), representing a major advance in the cfDNA liquid biopsy field. ${ }^{9,10}$ Among the various companion tests for the clinical management of NSCLC patients based on pathologic findings, clinical staging, and molecular profiling, ${ }^{2}$ the Cobas EGFR Mutation Test v2 was approved, by the US FDA, as a companion diagnostic test for patients under treatment for NSCLC with gefitinib, osimertinib, and erlotinib.

A portion of the plasma samples of lung cancer patients used in this study were stored before the introduction of the plasma EGFR test at our institution, and these patients could not benefit from the test. Therefore, in this study, we investigated the plasma EGFR mutation status using archived samples of lung cancer patients, which also allowed us to analyze the relationship of mutation status with survival.

However, to our knowledge, the feasibility of performing the Cobas EGFR Mutation Test v2 with archived plasma samples has not been assessed to date. Therefore, in this study, we evaluated the utility of using archived plasma samples for testing for EGFR mutations.

\section{Materials and Methods}

\section{Specimen collection, centrifugation, and storage}

This study was approved by the institutional review board of the Korea Institute of Radiological and Medical Sciences (KIRAMS) (K-1801-002-013). The included samples were K2 ethylenediaminetetraacetic acid (EDTA) anticoagulated remnant blood specimens from NSCLC patients after a complete blood cell count (CBC) test. The samples were provided by the KIRAMS Radiation Biobank (KRB). All plasma samples that were collected and archived under the protocol name of "lung cancer" were initially included for analysis. Samples from patients with a pathologically confirmed diagnosis of NSCLC and who had been tested for EGFR mutation using a tissue specimen were ultimately included in this study. All samples were stored at $4^{\circ} \mathrm{C}$ before centrifugation for 10 minutes at $2000 \times g, 4^{\circ} \mathrm{C}$. Plasma samples were then immediately archived in the biobank at $-70^{\circ} \mathrm{C}$. Specimen collection, centrifugation, and storage were all performed by the biobank.

\section{Specimen characteristics}

Information related to patient sex and age, histologic type, stage, chemotherapy history, date of chemotherapy, and survival status as well as the time of blood collection, centrifugation, and storage for each specimen, was provided by the biobank.

In addition, the designated honest broker of the biobank provided the initial result of the EGFR mutation test conducted using a tissue or cytological sample, which was performed on the PyroMark ID system (Qiagen, CA). This kit targets codon 719 in exon 18 , codons 768 and 790 in exon 20, codons 858 and 861 in exon 21, and deletions and complex mutations in exon 19. Information on the date of submission and type of specimen for the tissue/cytological EGFR mutation test was also available.

\section{Plasma EGFR mutation test}

cfDNA was extracted from each plasma sample using the Cobas cfDNA Sample Preparation kit (Roche Molecular Diagnostics, IN) initially, and then with the Maxwell ${ }^{\circledR}$ RSC ccfDNA plasma kit (Promega Corp., Madison, WI) owing to a change of laboratory policy during the course of the study, according to the manufacturer's instructions. The cfDNA concentration was measured using the Qubit dsDNA HS Assay kit (Invitrogen; Life Technologies, CA) on a Qubit 3.0 Fluorometer (Invitrogen; Life Technologies) according to the manufacturer's instructions. Plasma EGFR mutations were detected on the Cobas Z 480 analyzer (Roche Molecular System, Inc.) using the Cobas EGFR Mutation Test v2 per the manufacturer instructions for the 42 defined mutations, including the G719X substitution in exon 18, deletion mutations in exon 19, T790M and S768I substitution mutations in exon 20, insertion mutations in exon 20 , and L858R and L861Q substitutions in exon 21. All runs and sample validation were performed with Cobas 4800 software. If the run was deemed to be invalid, there was an insufficient volume of extracted DNA. If the run was deemed to be valid but the sample was invalid, there was an insufficient volume of extracted DNA for each sample. A positive and negative control sample from the Cobas EGFR mutation kit were included in each run of up to 30 samples. A run was regarded as valid if the EGFR mutant positive control and negative control were valid, according to the manufacturer's instructions. If either control result was invalid, the entire run was regarded as invalid, and the sample was excluded from analysis. 


\section{Comparison of plasma and tissue EGFR mutation results}

We reviewed the positive rate of EGFR mutation results from plasma and tissue or cytology testing and the concordance rate was determined by comparison of the two results. If the plasma EGFR result identified the exact same mutation as the tissue/cytology test, the result was regarded as "concordant." If the plasma test showed no or only partially overlapping mutations when the tissue/cytology test revealed one or more mutation, the result was regarded as "discordant." If the plasma test showed an additional mutation that was not detected in the tissue/cytology test, the results were also regarded as "discordant." The interval between the date of the tissue or cytology EGFR mutation test and blood collection was also considered in the analysis.

\section{Evaluation of the utility of archived plasma samples for a plasma EGFR mutation test}

The duration from blood collection to centrifugation was calculated, and samples were divided into groups that had been centrifuged within or $>4$ hours, according to the manufacturer's recommendation. The duration from storage of plasma to cfDNA extraction was also calculated, and samples were divided into groups that had been stored within or for $>12$ months per the manufacturer's recommendation.

The percent of valid results, positive rate of plasma EGFR mutation, and cfDNA concentration were analyzed according to these groups.

\section{Statistical analysis}

Fisher's exact test or chi-squared test was performed for analysis of categorical data. Quantitative data were compared using analysis of variance. Kaplan-Meier analysis and the log-rank test were conducted to analyze survival. A value of $p<0.05$ was considered statistically significant. All statistical analyses were performed using SPSS version 21 (SPSS, Inc., Chicago, IL).

\section{Results}

\section{Specimen characteristics}

A total of 116 plasma specimens were included for analysis, using samples that had been collected from May 2008 to May 2017. The characteristics of the specimens and patients are given in Table 1.

\section{Plasma EGFR mutation test}

cfDNA was extracted successfully from all specimens, with an average concentration of $39.8 \pm 23.8 \mathrm{ng} / \mathrm{mL}$. Although there was no difference in the positive rate of plasma EGFR mutation detected from cfDNA extracted with the two kits, the cfDNA concentration was higher when extracted with the Cobas cfDNA Sample Preparation Kit $(p<0.001)$ (Table 2). All runs for the plasma EGFR mutation test were deemed to be valid. The EGFR mutation was observed in $22(19.0 \%)$ plasma samples overall (Table 1). The plasma-positive EGFR mutation rate was higher in women $(p=0.035)$, but there was no difference according to histologic type $(p=0.167)$. The positive rate significantly varied according to stage $(p=0.015)$, with specimens from patients at stage IV showing the highest
Table 1. Specimen Characteristics and Plasma EPIDERMAL Growth FACTOR RECEPTOR Mutation Status

\begin{tabular}{|c|c|c|c|}
\hline \multirow{2}{*}{$\begin{array}{l}\text { Specimen } \\
\text { characteristic, } \\
\text { overall }\end{array}$} & \multirow{2}{*}{$\begin{array}{c}\mathrm{n}(\%) \\
\text { total }=116\end{array}$} & \multicolumn{2}{|c|}{$\begin{array}{c}\text { Plasma EGFR } \\
\text { mutation positive, } \\
\text { total plasma } \\
\text { EGFR mutation } \\
\text { positive, total }=22\end{array}$} \\
\hline & & $\mathrm{n}(\%)$ & $\mathrm{p}$ \\
\hline Age, years & $\begin{array}{c}\text { Median } \\
65(41-87)\end{array}$ & & \\
\hline $\begin{array}{l}\text { Sex } \\
\text { Female } \\
\text { Male }\end{array}$ & $\begin{array}{l}55(47.4) \\
61(52.6)\end{array}$ & $\begin{array}{r}15(27.3) \\
7(11.5)\end{array}$ & 0.035 \\
\hline $\begin{array}{l}\text { Histologic type } \\
\text { Adenocarcinoma } \\
\text { Adenosquamous } \\
\text { carcinoma }\end{array}$ & $\begin{array}{c}86(74.1) \\
1(0.9)\end{array}$ & $\begin{aligned} 21 & (24.4) \\
0 & (0.0)\end{aligned}$ & 0.167 \\
\hline $\begin{array}{l}\text { Bronchioalveolar } \\
\text { carcinoma } \\
\text { Large cell carcinoma } \\
\text { Squamous cell } \\
\text { carcinoma }\end{array}$ & $\begin{array}{c}1(0.9) \\
27(23.3)\end{array}$ & $\begin{array}{l}0(0.0) \\
0(0.0) \\
1(3.7)\end{array}$ & \\
\hline $\begin{array}{l}\text { Stage (TNM) } \\
\text { I } \\
\text { II } \\
\text { III } \\
\text { IV }\end{array}$ & $\begin{aligned} 35 & (30.2) \\
9 & (7.8) \\
22 & (19.0) \\
50 & (43.1)\end{aligned}$ & $\begin{array}{c}3(8.6) \\
0(0.0) \\
3(13.6) \\
16(32.0)\end{array}$ & 0.015 \\
\hline $\begin{array}{l}\text { Treatment } \\
\text { Chemotherapy } \\
\text { No chemotherapy }\end{array}$ & $\begin{array}{l}50(43.1) \\
66(56.9)\end{array}$ & $\begin{array}{c}16(32.0) \\
6(9.1)\end{array}$ & 0.030 \\
\hline
\end{tabular}

EGFR, epidermal growth factor receptor; TNM, tumor, nodes, metastases.

mutation rate. Specimens from patients who had undergone chemotherapy also showed a higher mutation rate than those without chemotherapy ( $p=0.030)$.

The details of the plasma EGFR mutation findings are given in Table 3. Twenty-six single mutations were detected in the 22 positive samples, and 4 samples showed 2 mutations concurrently. The exon 19 deletion (9.5\%) was the most frequent mutation observed, followed by L858R (6.9\%), T790M (4.3\%), G719X (0.9\%), and L861Q (0.9\%). The five $(4.3 \%)$ samples with the T790M mutation were all derived from patients who had received chemotherapy. There was no difference in the survival of the patients testing positive $(N=22)$ and negative $(N=94)$ for plasma EGFR mutation $(69.0 \pm 7.7$ months vs. $78.0 \pm 6.3$ months, $p=0.952$, overall: $79.0 \pm 5.6$ months), In addition, there was no difference in the survival of patients positive $(N=5)$ and negative $(N=111)$ for plasma EGFR T790M mutation (41.4 \pm 5.6 months vs. $79.3 \pm 5.6$ months, $p=0.922$, overall: $79.0 \pm 5.6$ months).

\section{Comparison with tissue or cytology EGFR results}

The plasma and tissue or cytology EGFR mutation tests were not conducted simultaneously, and the mean interval between conducting the two tests was 272.6 \pm 560.1 days. The tissue EGFR mutation was observed in $62(53.4 \%)$ samples, 3 of which showed two mutations concurrently. 
Table 2. Circulating Free DNA Concentration and Plasma Epidermal Growth Factor Receptor Mutation Positive Rate According to Circulating Free DNA Extraction Kit

\begin{tabular}{|c|c|c|c|c|c|}
\hline \multirow[b]{2}{*}{ cfDNA extraction kit } & \multirow[b]{2}{*}{$\mathrm{n}(\%)$} & \multicolumn{2}{|c|}{ cfDNA concentration } & \multicolumn{2}{|c|}{ Positive rate of plasma EGFR mutation test } \\
\hline & & $M e a n \pm S D$ & $\mathrm{p}$ & $\%$ & $\mathrm{p}$ \\
\hline $\begin{array}{l}\text { Cobas }^{\circledR} \text { cfDNA Sample Preparation kit } \\
\text { Maxwell }^{\circledR} \text { RSC ccfDNA plasma kit }\end{array}$ & $\begin{array}{r}14(12.1) \\
102(87.9)\end{array}$ & $\begin{array}{l}62.2 \pm 20.4 \\
36.7 \pm 22.6\end{array}$ & 0.000 & $\begin{array}{r}7.1 \\
20.6\end{array}$ & 0.465 \\
\hline
\end{tabular}

cfDNA, circulating free DNA; SD, standard deviation.

Similar to the plasma results, the exon 19 deletion $(30.2 \%)$ was the most frequent mutation detected, followed by L858R (20.7\%), G719X (2.6\%), T790M (1.7\%), and S768I $(0.9 \%)$. The positive rate of the plasma EGFR test was lower than that of the tissue/cytology test (Table 4). The complete list of EGFR mutations detected in all patients is provided in Supplementary Table S1.

The concordance rate between the two tests was $58.6 \%$. The sensitivity and specificity of the plasma EGFR mutation test was $33.9 \%$ and $98.1 \%$, respectively. Interestingly, five (4.3\%) samples showed T790M mutation in the plasma test, whereas the mutation was detected in only two (1.7\%) tissue/cytology samples. Only one specimen was positive in both tests, and four specimens were positive only in the plasma test. All the T790M-positive samples were obtained from patients who had received chemotherapy with TKIs before blood collection. Of the total five $(4.3 \%)$ samples that were additionally positive in the plasma (Table 5), three were T790M, one was T790M and L858R, and the other was L861Q. Two of these patients had died and the other three had progressive disease. However, there was no difference in survival according to additional plasma EGFR mutation $(p=0.348)$.

\section{Evaluation of the utility of archived plasma samples for the plasma EGFR mutation test}

All specimens were considered to be valid, regardless of interval between blood collection and centrifugation and storage. The positive rate and cfDNA concentration according to the preanalytical conditions that are given in Table 6. The mean duration from blood collection to centrifugation was $25.1 \pm 36.1$ hours (range: $0.0-172.7$ hours). A duration $>4$ hours did not influence the positive rate $(p=0.465)$ or

Table 3. Type and Number Plasma

Epidermal Growth Factor Receptor Mutation Detected In 22 Specimens

\begin{tabular}{|c|c|c|c|}
\hline \multirow{2}{*}{$\begin{array}{l}\text { Type of } \\
\text { plasma EGFR } \\
\text { mutation detected }\end{array}$} & \multirow{2}{*}{$\begin{array}{c}\text { Plasma EGFR } \\
\text { mutation detected } \\
(\text { total }=116), \mathrm{n}(\%)\end{array}$} & \multicolumn{2}{|c|}{$\begin{array}{c}\text { History of } \\
\text { chemotherapy }\end{array}$} \\
\hline & & With & Without \\
\hline G719X & $1(0.9)$ & 1 & 0 \\
\hline Exon19 del & $9(7.8)$ & 6 & 3 \\
\hline $\begin{array}{l}\text { Exon } 19 \text { del and } \\
\text { T790M }\end{array}$ & $2(1.7)$ & 2 & 0 \\
\hline T790M & $1(0.9)$ & 1 & 0 \\
\hline T790M and L858R & $2(1.7)$ & 2 & 0 \\
\hline L858R & $6(5.2)$ & 4 & 2 \\
\hline L861Q & $1(0.9)$ & 0 & 1 \\
\hline Total & $22(19.0)$ & 16 & 6 \\
\hline
\end{tabular}

cfDNA concentration ( $p=0.275)$. Similarly, the mean duration from plasma storage to cfDNA extraction was 9.6 \pm 25.0 months, and a duration of $>12$ months did not influence the positive rate $(p=1.000)$ or cfDNA concentration $(p=0.094)$.

\section{Discussion}

Molecular diagnosis is increasingly used for monitoring disease progression and identifying the patients' differential responses to potential therapies. ${ }^{1,2}$ The plasma EGFR mutation test is especially useful when archived tissue is not available. $^{21,22}$ We evaluated the feasibility of using archived plasma samples for the EGFR mutation test.

The positive rate of the plasma EGFR was lower than that of the tissue/cytology test. The relatively low positive rate of plasma mutations might be because of the time interval between the two tests, history of chemotherapy, or different analytical sensitivities. The plasma and tissue or cytology EGFR mutation tests were not conducted simultaneously, and $50(43.1 \%)$ patients had chemotherapy before the plasma EGFR mutation test. The limit of detection (LOD) for the plasma EGFR and tissue/cytology test used in this study was in the range of $0.6 \%-10.7 \%$ and $1.3 \%-13.4 \%$, respectively. Exon 19 deletion and the L858R mutation are less sensitive in plasma based on the LOD, and these are the most frequent mutations in EGFR. We postulate that the low positive rate in plasma resulted from the low sensitivity of the test for frequent mutations. Detection of T790M, S768I, and L861Q are more sensitive in the plasma EGFR mutation test. The high sensitivity of detecting T790M makes the plasma EGFR mutation test valuable for monitoring patients taking TKIs.

The positive rate was higher for women $(27.3 \%)$, patients with stage IV disease $(32.0 \%)$, and patients who had undergone chemotherapy (32.0\%). This higher positive rate for women is consistent with previous studies. ${ }^{21,22}$ The high positive rate for patients at stage IV might be because of the tumor shredding into the circulation during the metastatic process, whereas the higher positive rate for patients who had undergone chemotherapy might be related to the acquired mutation of T790M after TKIs treatment.

Interestingly, the T790M mutation was discovered more frequently $(4.3 \%)$ in the plasma than through tissue/cytology $(1.7 \%)$ samples. More than $50 \%$ of patients with lung cancer taking TKIs develop the T790M mutation, which requires treatment with osimertinib. $3,9,23,24$ Tissue biopsy is also recommended for these patients during disease progression. ${ }^{10}$ Thus, the plasma EGFR mutation test can be used to guide the choice of a suitable therapeutic agent and to monitor tumor responses throughout treatment without requiring invasive tissue biopsy. Patients who were positive for the plasma EGFR mutation or the T790M mutation specifically had shorter lives than those who were negative for the 
Table 4. Mutational Status Based on the Type of Specimen

\begin{tabular}{|c|c|c|c|c|c|c|c|}
\hline \multirow[b]{2}{*}{ Type of specimen } & \multirow[b]{2}{*}{ Total } & \multicolumn{2}{|c|}{ EGFR mutation positive } & \multirow[b]{2}{*}{ Subtype of tissue/cytology } & \multirow[b]{2}{*}{ Total } & \multicolumn{2}{|c|}{ EGFR mutation positive } \\
\hline & & $\mathrm{N}(\%)$ & $\mathrm{p}$ & & & $\mathrm{n}(\%)$ & $\mathrm{p}$ \\
\hline Plasma & 116 & $22(19.0)$ & 0.000 & - & - & - & - \\
\hline Tissue/cytology & 116 & $62(53.4)$ & & $\begin{array}{l}\text { Tissue }^{\mathrm{a}} \\
\text { Cytology }^{\mathrm{b}}\end{array}$ & $\begin{array}{l}82 \\
34\end{array}$ & $\begin{array}{l}39(47.6) \\
23(67.6)\end{array}$ & 0.048 \\
\hline
\end{tabular}

${ }^{\mathrm{a}}$ Tissue includes brain, lung, lymph node, and pleura.

${ }^{\mathrm{b}}$ Cytology includes bronchial washing, lung aspiration, peritoneal fluid, and pleural fluid.

mutation, but the differences were not statistically significant. This lack of statistical significance might be because of the small number of samples positive for these mutations in the plasma test.

Moreover, five $(4.3 \%)$ samples were additionally positive in the plasma test. Part of this difference could be explained by the time interval between the two tests, history of chemotherapy, or different analytical sensitivities of the assay. As the plasma and tissue or cytology EGFR mutation tests were not conducted simultaneously, changes in the disease course and treatment could have influenced the mutations.

A key limitation of this study is that we compared the results of plasma and tissue or cytology EGFR mutation tests that were not conducted simultaneously. The mean interval between the two tests was 272.6 \pm 560.1 days, and $50(43.1 \%)$ specimens were tested for plasma EGFR mutation status after the patients had received chemotherapy. In our study, the concordance rate $(58.6 \%)$ of EGFR mutations in the tissue and plasma was lower than that reported previously, ${ }^{18,20,25}$ which is mainly attributed to the relatively low detection rate $(33.9 \%)$ of plasma EGFR. Thress et al. ${ }^{25}$ reported sensitivity values of $82 \%, 87 \%$, and $73 \%$ for the exon 19 deletion, L858R, and T790M EGFR mutations, respectively. The differences between their findings and our present results may be related to differences in sample collection and analytical methods. Thress et al. collected blood samples from participants of the AURA trial, and the samples were centrifuged twice to collect plasma and extract circulating tumor DNA. The interval from blood collection and the first centrifugation is critical to ensure obtaining highquality cfDNA. By contrast, we used archived remnant plasma stored after a routine blood test. Thus, the interval between blood collection and the first centrifugation could not be well controlled, and the storage duration varied widely, ranging from 1 day to 98.4 months (mean $9.6 \pm 25.0$ months). Another possible reason for the low concordance rate in this study was that the blood samples were not collected at the same time point as the tissue biopsies. Accordingly, the matched plasma and tissue samples in our study were not time-concordant samples.

In addition, the processing time from blood collection to centrifugation is an important source of preanalytical variation with regard to DNA concentration, and thus the plasma should be centrifuged as soon as possible. ${ }^{8,26,27} \mathrm{We}$ used plasma samples with EDTA anticoagulated blood derived from remnant specimens after $\mathrm{CBC}$ tests. The whole blood sample is generally used for a CBC test, which does not need to be centrifuged. Because the remnant samples were archived after completion of CBC, most $(87.9 \%)$ of these specimens could not be centrifuged within the recommended time of 4 hours. However, we did not find a significant effect of the duration of blood collection to centrifugation on the plasma EGFR mutation test results.

Plasma samples can remain stable for up to 12 months when stored below $-70^{\circ} \mathrm{C}$, according to the manufacturer.

Table 5. Clinical Characteristics of Five Specimens Which Were Positive Additionally in Plasma

\begin{tabular}{|c|c|c|c|c|c|c|c|c|c|}
\hline No. & $\begin{array}{l}\text { Type of } \\
\text { plasma } \\
\text { EGFR } \\
\text { mutation } \\
\text { detected }\end{array}$ & $\begin{array}{l}\text { Type of } \\
\text { tissue } \\
\text { EGFR } \\
\text { mutation } \\
\text { detected }\end{array}$ & $\operatorname{Sex}$ & $\begin{array}{c}\text { Age } \\
\text { (years) }\end{array}$ & Histologic type & Stage & $\begin{array}{c}\text { History of } \\
\text { chemotherapy }\end{array}$ & $\begin{array}{c}\text { Chemotherapeutic } \\
\text { agent }\end{array}$ & Outcome \\
\hline 1 & $\begin{array}{l}\text { Exon19 } \\
\text { del and } \\
\text { T790M }^{\mathrm{a}}\end{array}$ & $\begin{array}{l}\text { Exon19 } \\
\text { del }\end{array}$ & Female & 76 & Adenocarcinoma & IV & Yes & Gefitinib & Dead \\
\hline 2 & $\begin{array}{l}\text { Exon19 } \\
\text { del and } \\
\text { T790M }\end{array}$ & $\begin{array}{l}\text { Exon19 } \\
\text { del }\end{array}$ & Female & 72 & Adenocarcinoma & IV & Yes & Gefitinib & $\begin{array}{c}\text { Progressive } \\
\text { disease }\end{array}$ \\
\hline 3 & $\begin{array}{l}\mathrm{L}^{858 \mathrm{R}^{\mathrm{a}}} \\
\text { and } \\
\mathrm{T} 790 \mathrm{M}^{\mathrm{a}}\end{array}$ & $\begin{array}{l}\text { Exon19 } \\
\text { del }\end{array}$ & Female & 79 & Adenocarcinoma & IV & Yes & $\begin{array}{l}\text { Gefitinib, } \\
\text { paclitaxel, } \\
\text { pemetrexed, } \\
\text { carboplatin, } \\
\text { etoposide }\end{array}$ & $\begin{array}{c}\text { Progressive } \\
\text { disease }\end{array}$ \\
\hline 4 & $\begin{array}{l}\text { L858R and } \\
\text { T790M }^{\mathrm{a}}\end{array}$ & L858R & Male & 56 & Adenocarcinoma & IV & Yes & Gefitinib & $\begin{array}{c}\text { Progressive } \\
\text { disease }\end{array}$ \\
\hline 5 & $\mathrm{~L} 61 \mathrm{Q}^{\mathrm{a}}$ & WT & Female & 76 & $\begin{array}{l}\text { Squamous cell } \\
\text { carcinoma }\end{array}$ & IV & No & None & Dead \\
\hline
\end{tabular}

${ }^{a}$ Mutation detected additionally in plasma.

WT, wild type. 
Table 6. Positive Rate and Circulating Free DNA Concentration According to Preanalytical Condition

\begin{tabular}{|c|c|c|c|c|c|}
\hline \multirow[b]{2}{*}{ Archiving condition } & \multirow[b]{2}{*}{$\mathrm{n}(\%)$} & \multicolumn{2}{|c|}{ Positive rate of plasma EGFR mutation test } & \multicolumn{2}{|c|}{ cfDNA concentration } \\
\hline & & $\%$ & $\mathrm{p}$ & Mean $\pm S D$ & $\mathrm{p}$ \\
\hline \multicolumn{6}{|c|}{ Duration from blood collection to centrifugation (hours) } \\
\hline Within 4 hours & $14(12.1)$ & 7.1 & \multirow[t]{2}{*}{0.465} & $46.3 \pm 39.4$ & \multirow[t]{2}{*}{0.275} \\
\hline Over 4 hours & $102(87.9)$ & 20.6 & & $38.9 \pm 20.9$ & \\
\hline \multicolumn{6}{|c|}{ Duration from plasma storage to cfDNA extraction (months) } \\
\hline Within 12 months & $98(84.5)$ & 19.4 & \multirow{2}{*}{1.000} & $38.2 \pm 24.3$ & \multirow{2}{*}{0.094} \\
\hline Over 12 months & $18(15.5)$ & 16.7 & & $48.4 \pm 19.0$ & \\
\hline
\end{tabular}

We extracted cfDNA using archived plasma samples from the biobank, with mean storage duration of $9.6 \pm 25.0$ months, and there was no effect of storage time on the results of the plasma EGFR mutation test.

In conclusion, our results suggest that the plasma EGFR mutation test will be especially useful when the archived tissue is not available, and archived plasma can serve as an alternative source under certain circumstances in NSCLC patients. Wider application of the use of archived samples could be greatly beneficial for patients by enabling personalized treatment and monitoring without requiring invasive and repetitive tissue biopsies.

\section{Acknowledgments}

This study was supported by a grant from the Radiation Bio-Resource Research Program of the Korea Institute of Radiological and Medical Sciences (KIRAMS), funded by the Ministry of Science and ICT (MSIT), Republic of Korea (50544-2018).

\section{Author Disclosure Statement}

No conflicting financial interests exist.

\section{Supplementary Material}

Supplementary Table S1

\section{References}

1. Wang $X$. Gene mutation-based and specific therapies in precision medicine. J Cell Mol Med 2016;20:577-580.

2. Wright S, Daker-White G, Newman W, et al. Understanding barriers to the introduction of precision medicines in non-small cell lung cancer: A qualitative interview protocol. Wellcome Open Res 2018;3. DOI:10.12688/ wellcomeopeners. 13976.1

3. Cabanero M, Tsao MS. Circulating tumour DNA in EGFRmutant non-small-cell lung cancer. Curr Oncol 2018; 25: S38-S44.

4. Passiglia F, Rizzo S, Di Maio M, et al. The diagnostic accuracy of circulating tumor DNA for the detection of EGFR-T790M mutation in NSCLC: A systematic review and meta-analysis. Sci Rep 2018;8:13379.

5. Brown NA, Aisner DL, Oxnard GR. Precision medicine in non-small cell lung cancer: Current standards in pathology and biomarker interpretation. Am Soc Clin Oncol Educ Book 2018;38:708-715.

6. van Draanen J, Davidson JP, Bour-Jordan H, et al. Assessing researcher needs for a virtual biobank. Biopreserv Biobank 2017;15:203-210.
7. Kim J, Jin H, Park J, et al. Comparison of three different kits for extraction of high-quality RNA from frozen blood. Springerplus 2014;8:76.

8. Arriola E, Paredes-Lario A, Garcia-Gomez R, et al. Comparison of plasma ctDNA and tissue/cytology-based techniques for the detection of EGFR mutation status in advanced NSCLC: Spanish data subset from ASSESS. Clin Transl Oncol 2018;20:1261-1267.

9. Sorber L, Zwaenepoel K, De Winne K, et al. A multicenter study to assess EGFR mutational status in plasma: Focus on an optimized workflow for liquid biopsy in a clinical setting. Cancers 2018;10:290.

10. Ulrich BC, Paweletz CP. Cell-free DNA in oncology? Gearing up for clinic. Ann Lab Med 2018;38:1-8.

11. Weber B, Meldgaard P, Hager H, et al. Detection of EGFR mutations in plasma and biopsies from non-small cell lung cancer patients by allele-specific PCR assays. BMC Cancer 2014; 14:294.

12. Kim Y, Shin S, Lee K. A comparative study for detection of EGFR mutations in plasma cell-free DNA in Korean clinical diagnostic laboratories. Biomed Res Int 2018;8: 7392419.

13. Marchetti A, Palma JF, Felicioni L, et al. Early prediction of response to tyrosine kinase inhibitors by quantification of EGFR mutations in plasma of NSCLC patients. J Thorac Oncol 2015;10:1437-1443.

14. Sugita S, Ito K, Moriya S, et al. EGFR-independent autophagy induction with gefitinib and enhancement of its cytotoxic effect by targeting autophagy with clarithromycin in non-small cell lung cancer cells. Biochem Biophys Res Commun 2015;22:28-34.

15. Kim HJ, Oh SY, Kim WS, et al. Clinical investigation of EGFR mutation detection by pyrosequencing in lung cancer patients. Oncol Lett 2013;5:271-276.

16. Fahoum I, Forer R, Volodarsky D, et al. Characterization of factors affecting the detection limit of EGFR p.T790M in circulating tumor DNA. Technol Cancer Res Treat 2018; 17:1533033818793653.

17. Morgillo F, Della Corte CM, Fasano M, et al. Mechanism of resistance to EGFR-targeted drugs: Lung cancer. ESMO Open 2016;1:e000060.

18. Zhang S, Zhu L, Chen X, et al. ctDNA assessment of EGFR mutation status in Chinese patients with advanced nonsmall cell lung cancer in real-world setting. J Thorac Dis 2018;10:4169-4177.

19. Barnes TA, O'Kane GM, Vincent MD, et al. Thirdgeneration tyrosine kinase inhibitors targeting epidermal growth factor receptor mutations in non-small cell lung cancer. Front Oncol 2017;7:113.

20. Bernabé R, Hickson N, Wallace A, et al. What do we need to make circulating tumour DNA (ctDNA) a routine diagnostic test in lung cancer? Eur J Cancer 2017;81:66-73. 
21. Cabanero M, Sangha R, Sheffield BS, et al. Management of EGFR-mutated non-small-cell lung cancer: Practical implications from a clinical and pathology perspective. Curr Oncol 2017;24:111-119.

22. Chabon JJ, Simmons AD, Lovejoy AF, et al. Circulating tumour DNA profiling reveals heterogeneity of EGFR inhibitor resistance mechanisms in lung cancer patients. Nat Commun 2016;14:13513.

23. Costa DB, Kobayashi SS. Whacking a mole-cule: Clinical activity and mechanisms of resistance to third generation EGFR inhibitors in EGFR mutated lung cancers with EGFR-T790M. Transl Lung Cancer Res 2015;4:809-815.

24. Santarpia M, Liguori A, Karachaliou N, et al. Osimertinib in the treatment of non-small-cell lung cancer: Design, development and place in therapy. Lung Cancer 2017;8:109-125.

25. Thress KS, Brant R, Carr TH, et al. EGFR mutation detection in ctDNA from NSCLC patient plasma: A crossplatform comparison of leading technologies to support the clinical development of AZD9291. Lung Cancer 2015;90: 509-515.

26. Ellervik C, Vaught J. Preanalytical variables affecting the integrity of human biospecimens in biobanking. Clin Chem 2015;6:914-934.

27. Markus H, Contente-Cuomo T, Farooq M, et al. Evaluation of pre-analytical factors affecting plasma DNA analysis. Sci Rep 2018;8:7375.

Address correspondence to:

Jin Kyung Lee, $M D, P h D$ Department of Laboratory Medicine Korea Cancer Center Hospital 75 Nowon-ro Seoul 01812 Republic of Korea

E-mail: jklee@kirams.re.kr 